\title{
EL CRÉDITO EN EL COMERCIO LANERO EN LA REGIÓN SORIANA DURANTE LOS SIGLOS XVI Y XVII ${ }^{1}$
}

\author{
MÁXIMO DIAGO HERNANDO \\ Consejo Superior de Investigaciones Científicas. Madrid
}

\section{RESUMEN}

El autor analiza en este trabajo el papel del crédito en las operaciones de venta de lanas realizadas en la región soriana durante los siglos XVI y XVI por los grandes y pequeños propietarios de ganado. Demuestra que los pequeños propietarios siempre contrataban la venta de sus lanas varios meses antes de su entrega para recibir préstamos de dinero de los mercaderes. Prueba que durante el siglo Xvi los grandes señores de ganado habitualmente vendieron sus lanas concediendo largos aplazamientos de pago a los mercaderes compradores, a cambio de obtener para las mismas precios muy elevados. $Y$ por fin pone de manifiesto que en el transcurso del siglo xvI estos grandes señores de ganado tuvieron que hacer frente a crecientes dificultades económicas, que les forzaron a solicitar con creciente frecuencia préstamos para atender los gastos de sus explotaciones ganaderas.

\section{ABSTRACT}

In this article the author pays attention to the role of credit in the negotiation of wool sales by big and small flockowners in the region of Soria during the sixteenth and the seventeenth centuries. He proves that the small floc-

N. de E.: Fecha de recepción del artículo en la Revista de Historia Económica: diciembre, 2000.

Fecha de aprobación del artículo por el Consejo de Redacción: mayo, 2002.

${ }^{1}$ Este trabajo se ha realizado en el marco de un proyecto de investigación sobre el comercio de lanas en Soria en la Edad Moderna, financiado por la Fundación Duques de Soria y dirigido por los profesores Felipe Ruiz Martín y Ángel Garcia Sanz. 
kowners always sold their wool several months in advance of its delivery, in order to borrow money from the merchants that bought it. Next he proves that during the sixteenth century the big flockowners usually sold their wool to the merchants on conditions and could delay the payment for a long period of time; they also obtained favorable very good prices for their products. Finally he proves that in the course of the seventeenth century the big flockowners of Soria had to face increasing financial difficulties that forced them to borrow money with increasing frequency in order to be able to preserve their flocks.

JEL Classification: N730.

\section{INTRODUCCIÓN}

Desde el siglo xv hasta comienzos del $\mathrm{xxx}$, el comercio de la lana fue una de las actividades económicas de mayor relevancia en el reino de Castilla, por tratarse de la principal mercancía que éste exportaba al resto de Europa, y existir además una importante demanda de este producto en el interior del reino para la fabricación de paños. A pesar de ello han proliferado poco los estudios dedicados al análisis de la organización del mercado lanero castellano en dicha época, y se han centrado sólo en algunos aspectos concretos del mismo, en especial en su última fase en territorio peninsular, cuando las lanas ya lavadas y ensacadas eran embarcadas en los puertos (Lapeyre, 1981, y Bilbao, 1983 y 1986), aunque también se ha prestado atención a algunas otras cuestiones como, por ejemplo, la participación en este mercado de ciertos monasterios propietarios de ganado trashumante, que vendían lana de elevada calidad y precio (Llopis, 1980, 1982 y 1998), o la tendencia en la evolución de los precios a largo plazo ${ }^{2}$.

Por consiguiente, continúa resultando notable nuestro desconocimiento sobre el funcionamiento del mercado lanero. Y este déficit consideramos que no puede ser adecuadamente cubierto mediante la realización de trabajos que, a partir del manejo de una masa documental muy restringida y parcial, pretendan generalizar los resultados a que haya dado lugar su análisis. Pues este mercado estaba estructurado de una forma muy compleja, al intervenir en él, por un lado, ganaderos de muy diverso perfil socioeconómico, que ponían a la venta lanas de muy variada calidad, y, por otro, mercaderes con muy diversa capacidad financiera, que trabajaban

${ }^{2}$ Hay que destacar la serie de precios que ofrece García Sanz (1977), a partir de las noticias de ventas de lana del cabildo segoviano. La más reciente recopilación de datos de precios de lanas en los siglos XVI, xVII y xvII, que recoge los aportados por diversas publicaciones anteriores, en Philipps (1997), pp. 249-74 y 305-25. 
para una clientela de potenciales compradores también muy diversificada. De manera que desde nuestro punto de vista una tarea previa que es necesario realizar es la de identificar a todos los grupos que tuvieron participación en el mercado lanero, para a partir de ahí poder dar cuenta del modo como unos y otros se relacionaron entre sí en él. Y para ello resulta preciso en primer lugar realizar estudios monográficos de carácter regional, a partir de los cuales se puedan plantear en una segunda fase análisis comparativos, y en una tercera fase se pueda por fin aspirar a la formulación de conclusiones de carácter sintético.

En aplicación de este principio metodológico hemos considerado oportuno, por consiguiente, dedicar un breve estudio monográfico a un ámbito geográfico restringido, el que comprende la ciudad de Soria y su entorno serrano más inmediato, para dar cuenta del modo como se organizaba el mercado lanero en un territorio en el que se dio en los siglos XVI y XVII un intenso tráfico de lanas de muy variada tipología, calidad y precio. Pero en esta ocasión nos vamos a centrar en el análisis de un único aspecto en concreto, el del papel.del crédito en los primeros estadios del comercio de lanas, cuando la materia prima pasaba de manos de los productores ganaderos a los primeros mercaderes que negociaban con ella. Pues hay que tener en cuenta que con posterioridad la lana cambiaba varias veces de manos hasta que llegaba a los consumidores finales, que eran los fabricantes pañeros. $Y$, cada vez que lo hacía, solían intervenir también operaciones de crédito, que desde una perspectiva global de estudio del funcionamiento del mercado lanero han de ser igualmente tenidas muy en cuenta. Pero, dadas las limitaciones del presente trabajo, no vamos a entrar en el análisis de estos estadios más avanzados del proceso de comercialización, para centrarnos, por el contrario, en determinar cómo el crédito asociado al comercio lanero afectaba al funcionamiento de las explotaciones ganaderas, dejando para ớra ocasión la clarificación de la cuestión del papel del crédito en el funcionamiento de las compañías mercantiles que trataban en lana.

Para abordar el análisis de la cuestión propuesta hay que partir de la constatación del hecho de que en la región soriana en los siglos xvI y XVII los ganaderos que surtían de lana al mercado fueron individuos de muy diverso rango sociopolítico y posición económica, que estaban al frente de explotaciones de dimensiones y orientación económica muy dispares. Pues los hubo que poseyeron rebaños que llegaron a superar las 20.000 cabezas de ovino trashumante, y otros, mayoritariamente propietarios de ganado estante, que ni siquiera llegaban a reunir medio centenar (Diago, 
1994). Y esta circunstancia influyó de forma decisiva en las condiciones de acceso de unos y otros al mercado lanero. Por lo cual, a la hora de dar cuenta del papel del crédito en las operaciones de venta de lanas efectuadas por los ganaderos sorianos, hemos considerado oportuno diferenciar entre las de pequeña envergadura, en las que se veían involucrados los pequeños propietarios, que representaban la inmensa mayoría si sumamos los estantes y los trashumantes, y aquellas otras que movilizaban mayores cantidades de dinero y lana, en las que participaba un reducido grupo de grandes propietarios de ganado trashumante, ya que unas $y$ otras respondían a una lógica de funcionamiento muy diferente.

Ciertamente este criterio de establecer una distinción entre pequeñas y grandes operaciones nos lleva a considerar conjuntamente dentro de las primeras a ventas de lanas de ganado estante, llamadas «churras», y trashumante, llamadas «estremeñas», a pesar de que el comercio de unas y otras respondía a lógicas de funcionamiento muy diferentes, según ya pusimos de manifiesto en algún trabajo anterior (Diago, 1991 y 2000a). Pero creemos que desde la perspectiva del análisis del papel del crédito en el comercio lanero es más conveniente proceder así, pues, además, aunque es cierto que los mercados de lanas «churras» y «estremeñas» estaban perfectamente diferenciados, de hecho eran bastantes los mercaderes, sobre todo sorianos, que tenían una activa participación en ambos al mismo tiempo.

\section{LAS PEQUEÑAS OPERACIONES DE CRÉDITO: ADELANTOS DE DINERO POR LOS MERCADERES A LOS MODESTOS PROPIETARIOS GANADEROS}

Entre las diversas variantes de operaciones de concesión de crédito asociadas a ventas de lanas que se practicaron en la región soriana en los siglos xVI y XVII, la más frecuente, a juzgar por el gran número de testimonios conservados en los protocolos notariales, fue aquella en la que el mercader adelantaba una modesta cantidad de dinero al ganadero, a cambio de que éste quedase comprometido a entregarle unos cuantos meses después una determinada cantidad de lanas. La razón que explica la sobreabundancia de este tipo de operación estriba en que la mayoría de los pequeños propietarios ganaderos se estuvieron desenvolviendo durante estos dos siglos en una situación de precariedad financiera crónica, y por ello se vieron año tras año forzados a comprometer la venta de sus lanas 
varios meses antes del esquileo, para conseguir así adelantos de dinero. $\mathrm{Y}$ este grupo de pequeños propietarios era extraordinariamente numeroso en la época, ya que integraba, por un lado, a una pléyade de campesinos dueños de diminutos hatos de ganado estante $y$, por otro, a los poseedores de pequeños rebaños de ganado trashumante, que eran muy numerosos en las comarcas serranas.

De hecho el recurso a las ventas anticipadas de lanas por parte de los propietarios de ganado estante, que vendían lanas de baja calidad y precio, estuvo en estos siglos absolutamente generalizado, a juzgar por el gran número de contratos conservados en los protocolos notariales, aunque no hay que descartar que también fuesen frecuentes las operaciones de venta con pago al contado concertadas en mercados y ferias. Mientras que, por el contrario, entre los ganaderos trashumantes nos encontramos con una situación mucho más diversificada, y que además experimentó apreciables alteraciones en el transcurso del tiempo. De forma que en el siglo XVI sólo en las comarcas serranas proliferaron con regularidad este tipo de operaciones de venta, efectuadas por pequeños propietarios que en muchos casos probablemente eran también pastores al servicio de medianos y grandes señores de ganados. Mientras que, por el contrario, otros muchos ganaderos de la cuadrilla soriana, dueños de rebaños trashumantes de tamaño medio e incluso en ocasiones más bien modesto, sólo recurrieron a la venta anticipada de sus lanas en este siglo de forma muy esporádica, y los grandes propietarios de hecho nunca lo hicieron.

Por otra parte, también conviene tener en cuenta que no todas las operaciones de venta adelantada de lanas respondían a la misma motivación, sino que en unas primaba el carácter de préstamo, mientras que en otras podía ser el interés de un mercader por asegurarse la adquisición de una determinada pila el factor determinante de la concertación. El primer caso se daba de forma prácticamente universal en las operaciones con lana «churra», concertadas por modestos campesinos que precisaban el dinero no sólo para atender los gastos de sus explotaciones ganaderas, sino también para garantizar la subsistencia de sus familias durante el largo invierno. Estas necesidades cabe presumir que apremiaban de hecho a la inmensa mayoría de los campesinos sorianos, pero los que tenían la fortuna de ser propietarios de ganado ovino, por muy pocas cabezas que poseyesen, estaban en mejores condiciones de acceder al mercado crediticio que quienes no lo poseían, ya que podían ofertar las lanas como garantía de rápida devolución de las cantidades recibidas en préstamo, siempre que no se produjese ninguna mortandad imprevista de ganado. $\mathrm{Y}$ así nos 
lo confirma la propia constatación del hecho de que en ocasiones, cuando individuos sin ganados se encontraron apremiados por muy graves necesidades financieras, recurrieron al expediente de solicitar a algún vecino suyo propietario ganadero que comprometiese por adelantado la venta de sus lanas, para así conseguir a través de él un préstamo de un mercader lanero. Como nos atestigua el caso de Francisco Romo, labrador vecino de Soria, quien, para poner remedio a una «necesidad muy forzosa» en que se encontraba, se concertó con otro labrador, Francisco de Martialay, para que éste comprometiese por adelantado en el otoño de 1619 la venta de 50 arrobas de lana «churra» de sus ganados a cambio de recibir prestados 50 ducados, que se destinarían a remediar su necesidad. Con el compromiso de que él le pagaría el valor de estas 50 arrobas en el mes de junio siguiente al precio que vendiesen entonces sus lanas otros vecinos de Soria ${ }^{3}$.

Dado que en los contratos de venta adelantada de pequeñas cantidades de lana primaba ante todo el carácter de operación de préstamo, era habitual que en el momento en que eran suscritos el mercader adelantase la práctica totalidad del precio en que quedaba valorada la mercancía que se había de entregar al tiempo del esquileo, en el mes de junio. $Y$ por esta misma razón se explica que muchos ganaderos en un mismo ejercicio concertasen sucesivamente varios contratos de venta anticipada, pues lo hacian conforme iban necesitando el dinero. Si bien con relativa frecuencia sus necesidades financieras llegaron a superar la capacidad de producción de lana de sus diminutos rebaños, y, por consiguiente, al llegar el plazo de entrega en el mes de junio, muchos no pudieron cumplir con sus compromisos, agravando por esta vía aún más su situación de endeudamiento. Pues, en efecto, en bastantes casos de incumplimiento de contrato los mercaderes exigieron que se les compensase por las cantidades de lanas o añinos que se les habían dejado de entregar, pagándoselas al precio al que se estuviesen cotizando en el momento en que debía haber tenido lugar la entrega, es decir, a precio de contado de verario, que era por supuesto muy superior al que se les había pagado a los ganaderos en el momento de la firma del contrato ${ }^{4}$.

${ }^{3}$ AHPS (Archivo Histórico Provincial de Soria), PN (Protocolos Notariales. Indicamos a continuación siempre número de caja, de expediente y de primer folio del documento), 234-475-246.

4 Un ejemplo en AHPS, PN, 226-462-296. Un vecino de Magaña habia vendido por adelantado a Pedro de Mondragón, mercader de Soria, 40 arrobas de añinos que le debía entregar en junio de 1614. Por habérsele muerto el ganado sólo pudo entregar 7 arrobas. Pedro de Mondragón transfirió el contrato de obligación a dos mercaderes portugueses 
En el capítulo de las ventas por adelantado de lanas «estremeñas» nos encontramos, sin embargo, un panorama mucho más diversificado, ya que si bien, por un lado, hubo entre los vendedores de este tipo de lanas propietarios muy modestos, que contrataban la venta de diminutas partidas con condiciones muy semejantes a las que se habían generalizado en el mercado de lana «churra», también proliferaron, por otro, individuos de posición económica relativamente desahogada, que en el momento de suscribir el contrato de venta sólo recibían anticipada una pequeña parte del total del precio en que se valoraba la partida que se obligaban a entregar. Porque en su caso el recurso al crédito tenía como objetivo prioritario atender necesidades financieras derivadas de la gestión de la explotación ganadera, que eran mayores que en el caso de los ganaderos estantes, y además tenían un componente estacional mucho más fuerte. Razón que explica que en bastantes contratos concertados en el otoño por éstos se contemplase que al adelanto de dinero efectuado por el mercader en el momento de su suscripción le siguiesen otros varios hasta el momento de la entrega de la mercancía. Como nos atestigua por ejemplo el suscrito por siete pequeños ganaderos trashumantes de Arguijo en septiembre de 1566, obligándose a entregar al mes de junio siguiente 700 arrobas de lana al mercader burgalés Luis de Castro, quien les haría efectivo su valor en los siguientes plazos: 1.680 reales al firmar el contrato, 2.520 el día de San Miguel (29 de septiembre), 4.900 puestos en Sevilla el día 1 de enero de 1567 y los 4.900 restantes en el momento de la entrega de las lanas en junio de $1567^{5}$.

Los contratos de venta anticipada los comenzaban a concertar cada año los pequeños propietarios a partir de julio, e incluso en casos extremos en el propio mes de junio, y se seguían concertando durante los meses

vecinos de Soria, a los que el de Magaña se comprometió por contrato de obligación de 11-VII-1614 a entregar 891 reales por el valor de las 33 arrobas de añinos que adeudaba a razón de 27 reales la arroba, «que es el precio que hoy (en julio) va y se venden en esta ciudad los añinos, antes a más preciom.

5 AHPS, PN, 76-172-139, Soria, 19-IX-1566. Otro ejemplo interesante en AHPS, PN, 397-708-550. Unos vecinos de Calderuela en septiembre de 1638 se comprometieron a entregar a Pedro Sánchez Salvador, mercader de Lumbreras, en junio siguiente las lanas y añinos que correspondiesen a 3.200 reales, de los cuales 1.000 les fueron adelantados en el propio momento de la concertación y los 2.200 restantes para mediados de marzo de 1639. Para calcular la cantidad de lanas que se debería entregar para devolver los 1.000 reales prestados en septiembre se aplicaría el precio al que se vendiesen en Castilfrío y Carrascosa en torno a San Miguel. Y para calcular la cantidad correspondiente a los 2.200 recibidos en marzo se aplicaría el precio al que se vendiesen en dichos lugares hacia Carnestolendas. 
siguientes, experimentando un notable incremento en número a comienzos del otoño, y después en la primavera, que era cuando preferentemente cerraban contratos los ganaderos trashumantes de rango medio. $\mathrm{Y}$, como es lógico, los precios ofrecidos por los mercaderes iban evolucionando en sentido ascendente en el transcurso de los meses, de manera que los más bajos solían ser los fijados en las operaciones concertadas a finales del verano, y los más altos los de los contratos de finales de la primavera. Porque, además, en estos últimos confluían dos circunstancias para hacer subir los precios. En primer lugar, que el período de tiempo por el que se adelantaba el dinero era más breve. $\mathrm{Y}$, en segundo lugar, que muchos de los que vendían entonces sus lanas eran medianos propietarios, que necesitaban en aquel momento dinero para pagar los arrendamientos de pastos de invernadero, a los cuales los mercaderes siempre estaban dispuestos a pagar mejores precios, porque cuidaban más la calidad de sus lanas y, además, estaban en condiciones de ofertar mayores cantidades. Pues, en efecto, se constata que cuanto mayores eran las partidas de lana comprometidas por contrato más alto era el precio que estaban dispuestos a pagar los mercaderes ${ }^{6}$. Y de ahí que con frecuencia algunos pequeños propietarios optasen por asociarse en compañías para concertar conjuntamente la venta de sus lanas, y obtener así mejores condiciones ${ }^{7}$.

Durante todo el siglo xvi y en las primeras décadas del xvI fue práctica habitual que al concertarse los contratos de venta anticipada por los pequeños propietarios se fijase ya el precio de la lana, de manera que el interés que el mercader cargaba por el dinero adelantado se camuflaba bajo la forma de fijación de un precio inferior al que se calculaba que se pagaría en el verano siguiente en las operaciones al contado. Pero, por supuesto, en esta forma de proceder siempre intervenía un elemento de riesgo, tanto para el comprador como para el vendedor, ya que no se podía excluir

${ }^{6}$ A mediados del siglo xviI el padre Calatayud sostuvo que eran más rentables para los mercaderes las adquisiciones de grandes partidas de lana porque «comprando de por junto, es menor el gasto de recogerla, labarla y conducirla». Calatayud (1761), p. 9. Cfr. Pérez Romero (1999), p. 46.

${ }^{7}$ En febrero de 1559 dos vecinos de Renieblas, uno de Narros y otro de Cuéllar, se obligaron conjuntamente a entregar a un mercader burgalés en el siguiente mes de junio 1.540 arrobas de lana. AHPS, PN, 13-32-43. En febrero de 1581 un vecino de Suellacabras se obligó a entregar a Juan de Álava, mercader de Soria, 136 arrobas de lana de los ganados trashumantes de seis convecinos suyos. AHPS, PN, 82-186-41. Y en marzo de 1581 un vecino de Buitrago se obligó a entregar en junio a unos mercaderes de Nájera 1.400 arrobas de su ganado y del de un vecino de Sotillo, cinco vecinos de Pedraza, dos de Portelrubio, dos de Dombellas y dos de Buitrago. AHPS, PN, 111-238. 
que en el transcurso de los meses los precios experimentasen una súbita alteración, en sentido positivo o negativo.

En el transcurso del siglo XVII, sin embargo, probablemente como reacción a la situación de enorme volatilidad de los precios provocada tanto por la política monetaria de la monarquía como por la propia inestabilidad del mercado lanero, se empezó a generalizar otro procedimiento de fijación de precios en los contratos de venta adelantada. $Y$ en virtud de este procedimiento, en lugar de acordarse un precio fijo para la lana en el momento de firmar el contrato de venta, se estipulaba tomar como referencia los precios que se pagasen a otros ganaderos que dispusiesen de lanas de calidad semejante. $Y$, además, se solía añadir una cláusula que disponía el descuento de cierto número de reales por arroba respecto del precio tomado como referencia, por virtud del cual se compensaba al mercader por el adelanto del dinero, aunque no se reconociese así de forma expresa ${ }^{8}$.

La gran mayoría de las operaciones de compra adelantada de lanas a pequeños ganaderos fueron concertadas por mercaderes avecindados en la ciudad de Soria y otros pequeños núcleos de su entorno, como Ágreda, Yanguas, San Pedro Manrique y las villas de Cameros, los cuales rara vez estuvieron involucrados en grandes empresas mercantiles, y mucho menos en empresas de exportación ${ }^{9}$. Algunos de ellos efectuaron las compras por encargo de mercaderes foráneos, a los que servían como agentes, pero también fue muy frecuente que se especializasen en el negocio de la reventa, que llevaban a efecto poco después de la adquisición de las lanas, en casos extremos antes incluso de haberlas recibido de los ganaderos. Pero desde esta perspectiva conviene diferenciar entre los mercaderes más modestos que se limitaron a tratar con lanas «churras», que revendían en su mayor parte a fabricantes pañeros de las comarcas de Soria y Cameros en partidas relativamente pequeñas (Diago, 1991 y 2000a), y los que al mismo tiempo también negociaron con lanás «estremeñas», quienes tenían como clientes principales a los mercaderes exportadores foráneos, aunque también surtían en pequeñas cantidades a los pañeros de la región, que si bien trabajaban preferentemente con lanas «churras», también empleaban algo de lana de ganado trashumante, sobre todo añinos (Diago, 2000a).

${ }^{8}$ Este mismo sistema de fijación de precios «en atención», con cláusula de descuento de cierto número de reales por arroba, es descrito para mediados del siglo xvin por el padre Calatayud. Vid. Calatayud (1761), p. 48. Sobre la aplicación de dicho sistema en Soria en el siglo xvin, vid. Pérez Komero (1999), pp. 46-47.

9 Esta situación contrasta con la que a principios del siglo xvi se daba en Cuenca, donde se denunció que sólo los mercaderes genoveses disponían de capital suficiente para adelantar a los ganaderos a cuenta de sus lanas. Benito Ruano (1975), pp. 123 ss. 
Los tratantes en lana «estremeña» fueron mucho menos numerosos entre los mercaderes sorianos que los tratantes en «churra», porque se trataba de una actividad que, a pesar de resultar mucho más lucrativa, exigía disponer de un importante capital susceptible de quedar inmovilizado durante varios meses, pues las partidas de lana con que se hacían los tratos eran bastante mayores, y más caras (Diago, 2000b). En concreto el negocio se basaba en adelantar dinero en otoño o primavera a los pequeños y medianos ganaderos trashumantes a fin de adquirir la lana a un precio relativamente bajo, para después revenderla durante los meses del verano o en los primeros del otoño siguiente al esquileo a un precio sensiblemente más alto a otros mercaderes, generalmente foráneos, a los que se solían conceder aplazamientos de pago de en torno a un año. De manera que para la buena marcha del negocio era preciso tener inmovilizado el capital durante un período relativamente prolongado de tiempo, ya que el dinero que se adelantaba a los ganaderos en otoño o en primavera no se recuperaba hasta por lo menos después de transcurrido un año, cuando empezaban a pagar los mercaderes a quienes se habían revendido las lanas recibidas a comienzos del verano. $\mathrm{Y}$ de ahí que estos mercaderes tuviesen con frecuencia que recurrir a ampliar su propio capital y el de sus familias y socios con el que les entregaban otros convecinos suyos, a veces miembros de la oligarquía soriana, para invertir «a pérdida o ganancia» (Diago, 2000b).

Los márgenes de ganancia obtenidos por los mercaderes sorianos en estas operaciones de compra y reventa de lanas «estremeñas» fueron muy variables, como no podía ser de otro modo, si tenemos en cuenta los innumerables factores que podían incidir en la rentabilidad del negocio, que además presentaba múltiples variantes. Pues en unos casos estos mercaderes revendían la lana cuando ésta se encontraba todavía dispersa en los esquiladeros de los ganaderos, o incluso sin haberse esquilado, mientras que en otros la entregaban a los compradores ya lavada y ensacada, bien en los lavaderos sorianos, o bien en los propios puertos del Cantábrico. Por lo que, en consecuencia, según las condiciones en que se entregase la mercancía, necesariamente habían de variar los precios conseguidos por ella, que a su vez estaban también influidos por las condiciones de pago estipuladas con el comprador, por no hablar de los factores que incidían en que los contratos de compra concertados con las ganaderos resultasen más o menos rentables para los mercaderes intermediarios. Pues no deja lugar a dudas sobre el diferente grado de rentabilidad de éstos el hecho de que con relativa frecuencia los mercaderes revendiesen al mismo precio varias partidas de lana que habían adquirido a precios diferentes. 
El análisis de algunos ejemplos nos puede permitir, sin embargo, conocer de forma aproximada los márgenes de ganancia concretos que consiguieron algunos intermediarios sorianos en las operaciones de reventa de lanas en sucio. $\mathrm{Y}$ así tenemos que Hernando Ibáñez vendió en julio de 1601 al portugués Francisco de Fonseca 850 arrobas por 640 mrs. la arroba, las cuales había adquirido a varios pequeños ganaderos trashumantes de la zona de Castilfrío en el anterior otoño a $500 \mathrm{mrs}$., de manera que obtuvo un margen de ganancia en la operación del 21 por $100{ }^{10}$. Unos márgenes más bajos, situados entre el 20 y el 15 por 100 , obtuvo en junio de 1608 el doctor Alonso de Santa Cruz, médico vecino de Soria, al revender a mercaderes portugueses instalados en Palencia 1.610 arrobas de lana que tenía compradas a diferentes ganaderos, al precio al que las había adquirido, que oscilaba entre 10 y 12,5 reales, incrementado en forma lineal en dos reales por arroba ${ }^{11}$. Y por fin en las numerosas operaciones concertadas por el licenciado Juan García, médico, en las dos primeras décadas del siglo XVI encontramos una amplia gama de márgenes de beneficio, que van desde un mínimo de un real hasta un máximo de cuatro reales por arroba.

\section{GRANDES OPERACIONES C.REDITICIAS: EL CRÉDITO DE LOS GANADEROS A LOS MERCADERES}

En la mayoría de los trabajos que han abordado el estudio del comercio lanero en la Castilla del siglo xvi sólo se encuentran referencias a operaciones de compra de lanas en que los mercaderes efectuaban adelantos de dinero a los ganaderos, hasta el punto de que se llega a tener la impresión de que esta práctica tuvo aplicación universal. $Y$, en efecto, al referirse a la actividad de los mercaderes burgaleses en este siglo autores como

${ }^{10}$ El contrato de reventa en Soria, 29-VII-1601, AHPS, PN, 60-139-231. Los de compra en este mismo protocolo. Aunque, por ejemplo, las 150 arrobas de Pedro de Neila, de Fuentelfresno, en lugar de a $500 \mathrm{mrs}$. se pagaron a 510 , todas se revendieron al mismo precio.

${ }^{11}$ Las lanas que le vendió las había comprado adelantadas a diversos vecinos de Carrascosa, Castilfrío, La Losilla, Fuentecantos, Estepa de San Juan, Suellacabras, Ausejo y Los Villares. De ellas, 600 arrobas las tenía ya almacenadas en su casa en Soria, las cuales declaró que le habían costado, incluyendo gastos de «recibo y costa», a razón de 12,75 reales por arroba. El precio que habian de pagar los portugueses por las 1.610 arrobas era el que habían costado más dos reales de ganancia por arroba, haciéndose efectivo el pago en dos plazos, San Lucas y Carnestolendas, la mitad en plata y la mitad en vellón. AHPS, PN, 218-446-128, Soria, 27-VI-1608. 
Basas y Lapeyre han llegado a sugerir que éstos recurrieron de forma sistemática a dicho modelo de contratación, que tenía como pieza clave el llamado «señalamiento», es decir, la entrega adelantada de una cantidad de dinero al ganadero, que sancionaba el compromiso de la adquisición de la lana del próximo esquileo ${ }^{12}$.

Ciertamente en apoyo de esta tesis se ha podido aducir el testimonio de algunos libros de cuentas de mercaderes burgaleses, como por ejemplo los de los Salamanca, de los que se deduce que la práctica totalidad de las adquisiciones laneras realizadas por ellos se llevaron a cabo según esta fórmula (Carrión de Íscar, 1995). Pero en contrapartida otros múltiples testimonios documentales, de fondos notariales y judiciales, demuestran que tanto los mercaderes burgaleses como otros muchos recurrieron a lo largo del siglo xvi con bastante frecuencia, sobre todo cuando adquirieron grandes partidas de lana, a otro modelo de contratación, en virtud del cual ellos no sólo no adelantaban dinero a los ganaderos, sino que por el contrario resultaban beneficiarios de una concesión de crédito, por cuanto se obligaban a pagar el precio de la mercancía adquirida en varios plazos después de su entrega, que siempre abarcaban varios años, y en casos extremos alcanzaban hasta diez.

Este modelo de contratación, como decimos, se empleó preferentemente en operaciones de venta de varios miles de arrobas, concertadas con los principales señores de ganados de la cuadrilla soriana. Pero con relativa frecuencia también lo encontramos empleado durante el siglo XVI en operaciones de menor envergadura concertadas con medianos propietarios, e incluso con algunos pequeños, que a veces se asociaban para vender conjuntamente sus lanas y obtener así mejores condiciones de venta. Y por regla general los aplazamientos de pago concedidos por los vendedores en estos casos eran mucho más cortos, pues raramente sobrepasaban los dos años.

El período en que hemos encontrado documentado mayor número de operaciones de este tipo, y las de mayor envergadura, comprende las décadas centrales del siglo XVI, cuando varios de los principales señores de ganados de Soria y Ágreda cerraron contratos de venta de enormes cantidades de lana, con frecuencia acumulada de los esquileos de varios años, concediendo aplazamientos de pago a los mercaderes compradores, que

12 Basas (1961), pp. 37-68, y (1963), pp. 231-264. Y Lapeyre (1981), p. 169. Otras obras de interés que aportan noticias sobre contratos de ventas de lana del siglo Xvi: Brumont (1984), Falah Hassan (1986) y Carrión de Íscar (1995). 
abarcaron períodos de tiempo de entre dos y diez años ${ }^{13}$. En estas operaciones los ganaderos obtenían unos precios por sus lanas muy superiores a los que se estipulaban en contratos en que se efectuaba el pago al contado, si bien nunca se llegaba a admitir explícitamente en los contratos que se pagaba interés por razón del aplazamiento de pago concedido. Pero en la mentalidad de los hombres de la época estaba ya bien arraigada la idea de que siempre que intervenían aplazamientos de pago había que compensar al que adelantaba el dinero con el abono de un interés, y éste se disfrazaba mediante la fijación de un precio más alto para la mercancía ${ }^{14}$. No obstante, todavía seguían existiendo conciencias muy escrupulosas, que consideraban que esta forma de proceder era esencialmente pecaminosa, por entender que la diferencia de precio existente entre las ventas «al fiado» y las ventas al contado representaba una ganancia ilícita, resultado de la práctica de la usura. Y así lo demuestra el hecho de que varios de estos grandes ganaderos sorianos que vendieron durante muchos años sus lanas «al fiado», al sentir cercano el momento de la muerte, quisieron poner remedio en sus testamentos a una situación que entendían que ponía en peligro la salvación eterna de su alma, exigiendo que se revisasen sus contratos de ventas de mercancías «al fiado», se determinase si en ellos había habido ganancia ilícita, y se devolviese la parte del precio que se estimase que se había cobrado indebidamente ${ }^{15}$.

Gracias a estas revisiones de contratos ordenadas por ganaderos con escrúpulos de conciencia y a algunos otros hallazgos documentales, referentes a ventas efectuadas por grandes ganaderos como el regidor Juan

${ }^{13}$ Refiriéndose a las décadas de 1540, 1550 y 1560, un contemporáneo manifestó que la mayor parte de los ganaderos trashumantes sorianos de cierto relieve «vendían al fiado por andar entonçes la dicha grangería con ganançia, sobra y descanso». AHPS, PN, 1602-2409-374.

${ }^{14}$ Un ejemplo de contrato en el que se admitía implícitamente que el tiempo por el que se fiaba la lana, y otras condiciones del contrato, influían en el precio fijado se puede encontrar en AHPS, PN, 141-296-234, Soria, 16-VIII-1611.

${ }_{15}$ Hemos localizado las revisiones de los precios de sus ventas de lanas ordenadas por Hernando Díaz de Fuenmayor y el bachiller Miguel Díaz de Fuenmayor, vecinos de Ágreda, en sus testamentos. La correspondiente a las ventas del primero entre 1559 y 1578 , en AHPS, PN, 1495-2238-444. Y la correspondiente a las del segundo entre 1546 y 1574, en AHPS, PN, 1602-2409-374. También nos consta que ordenó revisar sus ventas el regidor soriano Juan Alonso de Vinuesa, sobrino y heredero del regidor Juan de Vinuesa.

${ }^{16}$ Información sobre las ventas al fiado efectuadas por el regidor Juan de Vinuesa a partir de 1545 en Archivo de la Chancillería de Valladolid, Pleitos Civiles, Z. y Walls, Fenecidos, C. 585.1. Sobre la venta por este mismo en 1559 de cerca de 20.000 arrobas de lanas y añinos procedentes de cinco esquileos, que se fiaron por «una feria de Villalón y 8 octubres», en AHPS, PN, 49-119-384. Y sobre la venta de 18.500 arrobas de lana 
de Vinuesa ${ }^{16}$, hemos podido reconstruir las estrategias de comercialización de las lanas de varios de los principales señores de ganados trashumantes de la región soriana durante períodos relativamente prolongados de tiempo, siempre encuadrados en las décadas centrales del siglo XVI. Y, en efecto, a través del análisis de toda esta información hemos podido comprobar que entonces estos poderosos ganaderos acostumbraron a almacenar las lanas y añinos de hasta cinco esquileos, dándoles después salida a través de contratos de venta «al fiado», en virtud de los cuales terminaban de cobrar el valor de la mercancía vendida varios años después de haberla entregado a los compradores, aunque a cambio obtenían unos precios excepcionalmente altos por sus vellones ${ }^{17}$.

Las razones por las que estos grandes señores de ganados almacenaban las lanas de varios años, exponiéndose así al peligro de que se estropeasen, no alcanzamos a comprenderlas de forma plenamente satisfactoria. Pero lo que sí nos llama la atención es que sólo ellos recurrieron a este procedimiento, y que no lo hicieron una única vez, sino varias a lo largo de sus trayectorias al frente de sus explotaciones ganaderas trashumantes. Mientras que, por el contrario, los pequeños y medianos propietarios vendieron por lo regular ejercicio tras ejercicio, y a lo sumo almacenaron las lanas de un esquileo para darles salida al año siguiente. Por lo cual estimamos poco probable que se tratase de almacenamientos forzados por la falta de demanda, aunque no podemos entrar a determinar si esta estrategia de acumular en las lonjas lanas de tantos años fue en su momento la más racional, o por el contrario habría resultado más rentable y menos arriesgado para sus dueños avenirse a darles salida en plazos más breves, aun a costa de aceptar unas condiciones de venta más desfavorables.

Pero dejando a un lado el problema de los almacenamientos, otro hecho sobre el que conviene llamar la atención es que en los contratos concertados por los grandes señores de ganados sorianos en las décadas centrales del siglo XVI para dar salida a enormes partidas de lana, que en casos extremos

y añinos procedentes de los esquileos de los años 1568, 1569 y 1570, en unas cuentas en AHPS, 5049-24, fol. 15v.

17 Por ejemplo, Hernando Díaz de Fuenmayor vendió en 15592.222 arrobas de lana a $930 \mathrm{mrs}$. y 460 de añinos a $612 \mathrm{mrs}$. Ese mismo año Juan de Vinuesa vendió cerca de 20.000 arrobas de lana y añinos a $850 \mathrm{mrs}$. (cfr. nota 15). Pero en 1579 se seguían arrastrando pleitos entre las dos partes contratantes porque los mercaderes compradores sólo estaban dispuestos a pagar a razón de 18 reales $(612 \mathrm{mrs}$.) la arroba de lana, y de 14 reales (476 mrs.) la de añinos. Vid. AHPS, PN, 49-119-384. En un contrato de venta adelantada de 270 arrobas de lana concertado por dos vecinos de Castilfrío en febrero de 1559 se les pagaron a $569 \mathrm{mrs}$. AHPS, PN, 13-32-44. 
alcanzaron las 20.000 arrobas, se fijaron aplazamientos de pago extraordinariamente largos, que llegaron a abarcar hasta diez años. En ningún otro momento hemos constatado que se diese una situación semejante, pues fuera de esta época los aplazamientos de pago concedidos por los ganaderos sorianos a los mercaderes no sobrepasaron los dos años. $\mathrm{Y}$ ante esta constatación cabe preguntarse si tan generosas condiciones de pago fueron libremente ofertadas por los ganaderos, a cambio de conseguir unos mejores precios, o por el contrario las asumieron forzados por los mercaderes, que amenazarían en caso contrario con no comprar. Como en toda transacción es probable que las dos partes tuviesen su cuota de responsabilidad. Pero en cualquier caso lo cierto es que si los ganaderos accedían a esperar varios años para terminar de cobrar el precio de las lanas, y al mismo tiempo se mostraban capaces de dejar de venderlas durante varios ejercicios, almacenándolas en sus lonjas, es porque se encontraban en una situación de desahogo financiero, al menos relativo. Mientras que en contrapartida los mercaderes no parece probable que anduviesen entonces sobrados de capital, o al menos debían tener la mayor parte del mismo inmovilizado, pues de lo contrario hubiesen accedido a acortar los plazos a cambio de la fijación de unos precios inferiores para la mercancía.

Precisamente la constatación del hecho de que en estas operaciones los ganaderos obtuvieron por sus lanas unos precios muy elevados nos invita a presumir que no fueron ellos la parte colocada en posición de mayor debilidad a la hora de negociar las condiciones de la venta, por razón de existir escasa demanda en el mercado. Pues si efectivamente hubiesen tropezado con dificultades para dar salida a sus lanas, por falta de demanda, y en consecuencia se hubiesen tenido que doblegar a aceptar las condiciones que les impusiesen los mercaderes, resulta difícil explicar que éstos accediesen a pagar precios tan altos, y además por partidas de lanas de tal magnitud. Por el contrario, presumimos que a los mercaderes exportadores, burgaleses en su mayoría, les interesaba adquirir las lanas de estos grandes señores de ganados sorianos, aunque tuviesen que pagar por ellas precios muy elevados, porque eran conscientes de que les podían dar fácilmente salida en Flandes o en Francia gracias a su buena reputación, obteniendo además un buen margen de beneficio. Pero no podrían comprometerse a adquirirlas salvo en el caso de que se les concediesen unas buenas condiciones de pago, dado que el capital que se requería para la inversión era elevadísimo.

Si los grandes señores de ganados sorianos de mediados del xvi adoptaron conscientemente una estrategia especulativa a la hora de gestionar 
sus explotaciones ganaderas es algo que no podemos determinar con seguridad a partir de las informaciones de las que hasta ahora disponemos, aunque diversos indicios nos invitan a sospecharlo. Pero lo que sí sabemos con certeza es que el procedimiento de concertación de venta de lanas que emplearon entonces les hizo incurrir en enormes riesgos, y les provocó más de un quebradero de cabeza. Pues los mercaderes más de una vez incumplieron los plazos de pago, o los interpretaron en un sentido desfavorable para el ganadero cuando iban referidos a ferias de Medina del Campo, y en alguna ocasión incluso iniciaron procedimientos legales para forzar una rebaja de los precios concertados en los contratos de obligación, alegando que en éstos había intervenido usura.

Pero a pesar de estos indudables riesgos, entendemos que este tipo de operaciones resultaron extraordinariamente provechosas para los ganaderos que las realizaron, puesto que sabemos que varios de ellos en el transcurso del siglo XVI consiguieron enriquecerse de forma sorprendente ${ }^{18}$, y efectuaron importantes inversiones en adquisiciones de juros, en alguna ocasión financiadas directamente con el producto de la venta de grandes partidas de lanas ${ }^{19}$. Aunque para determinar con más seguridad y precisión en qué medida los beneficios obtenidos en estas operaciones de venta de lana tan arriesgadas contribuyeron al enriquecimiento de estos ganaderos habría que profundizar más en el análisis de la documentación disponible, intensificando además los trabajos de exploración en el Archivo de Chancillería y en los de protocolos de ciudades como Burgos, Medina del Campo, Medina de Rioseco, Villalón, Valladolid y Madrid.

${ }^{18}$ Referencias al proceso de ascenso socioeconómico de familias ganaderas en Soria en el siglo xvi en Diago (1993). Destacaremos que al regidor Juan de Vinuesa su mujer Beatriz de Beaumont le llegó a reclamar por «gananciales» nada menos que 200.000 ducados (p. 478).

19 El alférez Francisco López de Río vendió en agosto de 159014.600 arrobas de lanas y añinos procedentes de los esquileos de 1588, 1589 y 1590, a condición de que el mercader comprador le adquiriese a su nombre un privilegio de juro de heredad, que rentase 1 millón de mrs. anuales, para empezar a gozar de él desde el 1 de enero de 1591 , el cual no habría de costarle más de 17 millones de mrs., a pesar de que en principio su precio debía ascender a 20 millones, ya que estos juros se vendian a razón de 20.000 el millar. Finalmente el valor de las lanas sólo alcanzó para pagar la mitad de los 17 millones que costó el juro, y la otra mitad se pagó en efectivo. AHPS, PN, 145-303-198 y 232. Gracias a este y otros once juros adquiridos por la familia con anterioridad, el alférez Antonio López de Río, yerno y sucesor de Francisco, percibía cada año a principios del siglo xvI cerca de 2,5 millones de mrs. y 1.800 fanegas de cereal con cargo a las rentas de la monarquía en el partido de Soria. Y además de estos juros la familia poseía otros situados sobre rentas de otros partidos. 


\section{GRANDES OPERACIONES CREDITICIAS: EL CRÉDITO DE LOS MERCADERES LANEROS A LOS GRANDES PROPIETARIOS GANADEROS}

El período de bonanza de las grandes explotaciones ganaderas trashumantes sorianas se prolongaría hasta comienzos de la década de 1570 , cuando podemos constatar que algunas de ellas comenzaron a generar pérdidas en varios ejercicios ${ }^{20}$, como resultado probablemente de la negativa evolución del mercado internacional lanero, que dio lugar a los primeros drásticos descensos de precios. Este primer bache se superó con relativa facilidad, pero en las décadas de 1580 y 1590 volvieron a reaparecer los problemas, en forma aún más agravada. Y como consecuencia algunos grandes ganaderos sorianos, que habían incurrido en grandes riesgos al asumir una forma de gestión de sus explotaciones ganaderas trashumantes de marcado carácter especulativo, tuvieron que hacer frente en el tránsito del siglo XVI al XVII a dificultades que les colocaron al borde de la bancarrota ${ }^{21}$.

Otros colegas suyos consiguieron, sin embargo, salir airosos de aquella difícil coyuntura, no sin realizar importantes esfuerzos de adaptación a las nuevas circunstancias del mercado, por ejemplo tomando a su cargo la comercialización de sus lanas en Italia durante varios ejercicios. Pero aunque, una vez superado este bache, en el transcurso de las primeras décadas del siglo XVI tuvo lugar una cierta recuperación del mercado lanero, ya no se volvieron a repetir en adelante los tiempos de bonanza de las décadas centrales del siglo xvI, y con relativa frecuencia se produjeron bruscas caídas de los precios de la lana, como la que tuvo lugar en 1607. Y esta evolución tuvo su reflejo en la progresiva modificación de los procedimientos de concertación de venta de sus lanas por parte de los grandes señores de ganados sorianos. Pues, en efecto, aunque éstos en las primeras décadas del nuevo siglo continuaron concediendo aplazamientos de pago a los mercaderes a quienes se las vendían, acortaron drásticamente los plazos, que ya en ningún caso superaron los dos años contados a partir del momento de la entrega de la mercancía. $Y$, además, también comenzaron a recurrir ocasionalmente a un procedimiento de contratación del que se habían mantenido en gran medida al margen en el siglo anterior, la venta por adelantado de lanas a cambio de recibir un préstamo de los mercaderes.

${ }^{20}$ La explotación ganadera del regidor soriano Juan de Vinuesa y de su sobrino Juan Alonso de Vinuesa generó unos beneficios entre 1557 y 1572 de un total de 22.257.013,5 mrs. Pero en los años 1569, 1571 y 1572 tuvo pérdidas. AHPS, 5049-24.

${ }^{21}$ Análisis del caso paradigmático del regidor Alonso de Río, el menor, en Diago (2001a). 
Este procedimiento que, como hemos visto, se aplicó de forma generalizada en las operaciones de compraventa de pequeñas cantidades de lana tanto en el siglo XVI como en el XVI, también fue empleado en sus contratos en bastantes ocasiones por los medianos propietarios durante el siglo XVI. Pues éstos combinaron entonces las ventas efectuadas en el verano al contado o con concesión de aplazamiento de pago a los mercaderes, con las concertadas en otoño o durante la primavera con cargo al esquileo del siguiente verano, a cambio de recibir adelantos de dinero, que por lo general sólo representaban una parte del precio total. Y optaron por un procedimiento u otro en función de cuál fuese su situación financiera en cada momento y de los cambios en la predisposición de los mercaderes. Pues cabe presumir que éstos, cuando dispusiesen de excedentes importantes de capital para emplear y advirtiesen la existencia de una fuerte demanda en los mercados internacionales, se mostrarían más dispuestos a invertir dinero en la entrega de adelantos para así tener asegurada la adquisición de más pilas y a precios más ventajosos.

Pero, por el contrario, los grandes señores de ganados trashumantes no comenzaron a recurrir a la concertación de este tipo de operaciones hasta el siglo xvI, y durante su primera mitad sólo lo hicieron de forma esporádica, en años particularmente difíciles en que se vieron apremiados por graves problemas financieros. De manera que, por ejemplo, los dos principales señores de ganados de la cuadrilla soriana, el alférez Francisco López de Río e Íñigo López de Salcedo, concertaron por adelantado la venta de sus lanas del esquileo de 1626 en noviembre de 1625 y enero de 1626 , respectivamente, por unos precios bastante bajos, a cambio de recibir cuantiosas cantidades en préstamo para saldar deudas ${ }^{22}$. Pero sólo se trató de una operación aislada, ya que en los siguientes ejercicios, también caracterizados por malas condiciones en el mercado, ambos optaron por otras alternativas como almacenar las lanas, en el caso de Íñigo López de Salcedo ${ }^{23}$, o llevarlas a vender lavadas a Francia, en el caso del alférez.

En 1642 de nuevo los grandes señores de ganados se vieron apremiados por graves dificultades financieras, y por ello volvieron a contratar por

${ }^{22} \mathrm{El}$ alférez vendió en XI-1625 por 33,5 reales de vellón por arroba, para pagar 2.111.800 mrs. que debía del aprovechamiento de las dehesas de La Serena del ejercicio 1624-1625, del plazo que cumplía el 1-XI-1625. AHPS, PN, 451-791-280. Ínigo López de Salcedo, por contrato de enero de 1626 , vendió a 34,5 reales por arroba. AHPS, PN, 452-792-159. Por contraste el mercader soriano Julián Martínez vendió en el verano de 16263.306 arrobas a 40 reales.

${ }^{23}$ Éste no vendió lanas ni en 1627 ni en 1628 , mientras que en 1629 vendió 4.081 arrobas, $y$ en 1630, 6.269 arrobas de lana soriana, 1.835 de lana segoviana, 1.127 de añinos sorianos y 250 de añinos segovianos. En ambos casos los mercaderes pagaron a plazos. 
adelantado la venta de sus lanas, pero aún lo pudieron seguir haciendo desde una posición de relativa fuerza, como lo demuestra el hecho de que consiguieron unas buenas condiciones para la fijación del precio ${ }^{24}$, o incluso a alguno se le dejó abierta la posibilidad de anular la operación si cambiaban las normas reguladoras del mercado lanero ${ }^{25}$. Por lo que no consideramos descartable que en la concertación de estos contratos influyese tanto el interés del mercader por asegurarse la adquisición de las pilas de más prestigio, como la necesidad de los ganaderos de obtener préstamos, que en ningún momento fue disimulada, al hacerse constar en los propios contratos que el dinero adelantado se destinaría a saldar deudas de pastos.

Poco a poco, no obstante, conforme fue avanzando el siglo las dificultades financieras terminaron convirtiéndose en un problema crónico para todas las grandes explotaciones ganaderas trashumante sorianas, sobre todo a partir de la década de 1660 . Y como consecuencia éstas pasaron a depender cada vez más de los adelantos de dinero que les pudiesen efectuar los mercaderes interesados en la compra de sus lanas. De manera que a partir de entonces los grandes propietarios ganaderos sorianos ya no recurrieron a la venta adelantada de sus lanas sólo de forma esporádica, en circunstancias especialmente adversas, sino que éste pasó a convertirse para ellos en un procedimiento habitual de venta, empleado de forma regular año tras año, como lo había sido por los pequeños propietarios en el siglo Xvi. E incluso algunos llegaron a acumular una deuda tan abultada con los mercaderes que se vieron obligados a comprometer por adelantado la entrega de las lanas de varios esquileos para saldarla ${ }^{26}$. Pero en ningún

${ }^{24}$ Dos ganaderos de la familia Ríos que vendieron conjuntamente 4.600 arrobas al flamenco Esteban Adón obtuvieron un precio mínimo de 47 reales por arroba, con la condición de que si en Soria y su tierra se concertaban a precio superior operaciones de venta de lanas sorianas del esquileo de 1642, con pago al contado, se les habrían de pagar a ellos las suyas a ese precio incrementado en 2,5 reales por arroba. AHPS, PN, 465-807-209. La inclusión de esta cláusula de revisión de precio resultó muy favorable para los vendedores porque entre marzo y agosto se produjo una brutal subida de precios. En concreto el 8-VIII-1642 se declaró que el precio más alto que había entonces abierto en Soria y su tierra era el de una partida de lanas de 2.000 arrobas comprada a 69 reales de vellón por arroba. AHPM (Archivo Histórico de Protocolos de Madrid), 4706, s. f.

${ }^{25}$ Don Juan de Salcedo, vecino de San Andrés, vendió con condición de que en caso de que se publicase pragmática regulando el precio de las lanas, el contrato de venta quedase anulado, si devolvía el dinero recibido como adelanto. AHPS, PN, 465-807-208.

${ }^{26}$ Un ejemplo en AHPS, PN, 782-1266-73, Soria, 6-VIII-1671. Juan de Salazar y Salcedo se obligó a entregar a los mercaderes navarros Juan Morales y Joseph de Miñano las lanas de los esquileos de sus ganados de los ejercicios de 1672,1673 y 1674 , a cambio de adelantos en dinero, que llegaron a ser, no obstante, de tal cuantía que, cuando el 
caso se llegó a la situación en que se vieron sumidos muchos monasterios ingleses en el siglo XII, cuando los grandes mercaderes exportadores italianos les adelantaban fuertes sumas de dinero para obligarles a que se comprometiesen por adelantado a entregarles la lana de sus rebaños de hasta diez esquileos (Burton, 1994, y Kershaw, 1973). Si bien hay que tener en cuenta que en la segunda mitad del siglo xvII los mercaderes laneros no participaban del mismo interés que había animado a los italianos a adquirir en el siglo xm las lanas de los monasterios ingleses, que gozaban de una excelente reputación y eran muy demandadas en el continente europeo. Pues, aunque entonces las lanas de los rebaños de los grandes señores de ganados sorianos habían alcanzado un alto prestigio en los mercados europeos, inferior, no obstante, al de las segovianas y leonesas, la demanda de este producto había entrado en una fase de fuerte depresión, y por tanto no se daban las circunstancias para que los mercaderes compitiesen por su captación.

En este contexto resulta comprensible, por otra parte, que los mercaderes consiguiesen imponer unas condiciones de precios más duras a los grandes señores de ganados, una vez que éstos habían perdido el margen de maniobra para la negociación del que habian dispuesto en el pasado, sobre todo cuando eran ellos los que asumían el papel de prestamistas al conceder aplazamientos de pago a los mercaderes. Y, en efecto, en algunos contratos comenzó a hacerse por primera vez referencia explícita a la exigencia del cobro de un interés por el adelanto del dinero, que se efectuaba mediante la fórmula del descuento de varios reales por arroba respecto del precio fijado para la operación por el procedimiento de las «atenencias», es decir, por referencia al precio obtenido por las pilas de otros ganaderos de igual reputación ${ }^{27}$. Pero lo habitual siguió siendo que dicha exigencia fuese disimulada por el empleo de fórmulas «piadosas».

En numerosos contratos, no obstante, aunque no se reconoció expresamente el cobro de intereses, la fijación del precio final de la lana por el procedimiento de atenencia, con cláusula de descuento de varios reales

10 de agosto de 1673 se volvieron a juntar ambas partes para ajustar cuentas, Juan de Salazar les quedaba todavía debiendo 121.568 reales de vellón. Y, dado que sus lanas del esquilmo de 1674 no podían llegar a alcanzar este valor, debió obligarse entonces a entregarles también las del año 1675, para con el valor de unas y otras amortizar la deuda.

${ }^{27}$ En diciembre de 1653 dos miembros de la familia Salcedo vendieron sus lanas del esquileo de 1654 a Juan Bautista de Aguirre y Gamarra, mercader de Estella, que entonces les adelantó 48.000 reales, y otros 16.500 reales a cada uno de ellos el 1 de marzo de 1654. Para compensarle por la anticipación del dinero se dispuso que del precio que finalmente se fijase para las lanas se descontase 1,5 reales por arroba. AHPS, PN, 662-1097-774. 
por arroba respecto al precio de los «atenidos», permite presumir que dicho descuento equivalía de hecho al interés. Pero en muchos otros contratos, por el contrario, los ganaderos que recibían adelantadas importantes cantidades de dinero consiguieron a pesar de ello que se les garantizase el pago de unos precios similares a los que podrían haber conseguido de haber vendido al contado, puesto que no se preveía efectuar descuentos de los precios a los que vendiesen sus lanas los ganaderos designados como «atenidos» ${ }^{28}$. Por lo cual en una primera aproximación se podría pensar que en estas operaciones no se cobró de hecho interés. Si bien estamos convencidos de que no fue así, porque se debió recurrir a un subterfugio para camuflarlo, consistente en hacer constar en el contrato que el ganadero había recibido prestada una cantidad de dinero superior a la efectivamente entregada por el mercader prestamista. Fórmula que, por otra parte, debió ser también la empleada para ocultar el cobro de intereses en otros múltiples contratos de obligación que a partir de la década de 1660 suscribieron estos mismos ganaderos para obtener préstamos de elevadas cantidades de dinero con las que atender los gastos generados por sus explotaciones ganaderas trashumantes, sin comprometer la venta de sus lanas al prestamista, casi siempre por expreso deseo de éste. Pues, en efecto, ésta fue una modalidad de contratación que hizo su aparición por primera vez en la segunda mitad del siglo xvII, y alcanzó entonces gran difusión en la región soriana, como comprobaremos a continuación.

\section{CRÉDITO PARA LOS GRANDES GANADEROS TRASHUMANTES AL MARGEN DE LA CONTRATACIÓN LANERA}

Dado que, al menos desde mediados del siglo XvII, los grandes señores de ganados sorianos comenzaron a mostrarse incapaces de asegurar con sus propios medios financieros el mantenimiento de sus explotaciones ganaderas trashumantes, pasaron a verse forzados a partir de entonces a tener que solicitar prestadas regularmente elevadas cantidades de dinero para hacer frente a los gastos que éstas generaban. Y poco a poco los ingresos

${ }^{28}$ En diciembre de 1663 Rodrigo de Salcedo Camargo se obligó a entregar al mercader soriano Juan Mateo Gutiérrez unas 3.200 arrobas de lanas y añinos, a cambio de recibir adelantados 125.000 reales de vellón en varios plazos. El precio se fijó por el procedimiento de «atenencias» en unas condiciones muy favorables para el ganadero. AHPS, PN, 672-1107-1062. 
obtenidos en primavera y verano de la venta de las lanas y carneros empezaron a resultar insuficientes para devolver estas cantidades tomadas a préstamo. De manera que progresivamente fueron entrando en una espiral de endeudamiento, que pronto les llevó a algunos de ellos a tropezar incluso con dificultades para encontrar personas o comunidades dispuestas a prestarles dinero. Puesto que, aunque en una primera fase muchos mercaderes estuvieron dispuestos a adelantarles dinero a cambio del compromiso de la entrega posterior de sus lanas, pronto éstos comenzaron a mostrarse remisos a comprometerse en la adquisición de grandes partidas de esta mercancía varios meses antes de la fecha prevista para su entrega, probablemente porque el descenso de la demanda en los mercados europeos y los peligros que para el comercio generaban las guerras contra Francia les forzaron a actuar con precaución, ante el temor de no poder darle salida ${ }^{29}$.

En consecuencia, los ganaderos se vieron obligados a buscar otras fuentes de financiación para sus explotaciones ganaderas al margen de la contratación lanera. $\mathrm{Y}$, en primer lugar, una muy importante la encontraron en los propios mercaderes con los que hasta entonces habían estado concertando contratos de venta adelantada de lanas. Pues, en efecto, nos consta que éstos continuaron adelantando importantes cantidades de dinero a partir de comienzos del otoño a los principales señores de ganados, con la condición de que se las devolviesen en el transcurso del mes de julio siguiente, si bien en los contratos de obligación evitaron comprometerse de antemano a adquirir cantidad alguna de lana ${ }^{30}$. Pero en contrapartida sí incluyeron habitualmente en ellos una cláusula que disponía que, si llegado el momento del esquileo les interesase la compra de las lanas del ganadero a quien efectuaban el préstamo, éste amortizase con ellas la deuda.

Por lo tanto, el recurso creciente por parte de los mercaderes laneros que operaron en la región soriana a partir de la década de 1660 a este modelo de contratación habría que explicarlo ante todo como una medida de precaución para evitar comprometerse con demasiados meses de adelanto a adquirir grandes partidas de lana, ante la imprevisible evolución

${ }^{29}$ Algunos ejemplos que ilustran esta evolución en la actitud de los mercaderes en Diago (2001b), pp. 150-156.

${ }^{30}$ Un mismo ganadero podía recibir varios préstamos de un mismo mercader en el transcurso de un mismo ejercicio. Simón Martínez de Mendoza recibió prestados 4.400 reales de Juan Mateo Gutiérrez el 3-XI-1661, y otros 4.300 el 24-XII-1661. AHPS, PN, $670-1105.678$ y 868 . 
del mercado lanero en un contexto caracterizado por una extrema inestabilidad. Porque de hecho puede comprobarse que con bastante frecuencia dichos mercaderes finalmente adquirieron las lanas de los ganaderos a los que habían prestado dinero con estas condiciones. Y, además, se constata que en los mismos ejercicios en que recurrían a este modelo de contratación en la negociación con los grandes ganaderos cerraban también numerosos contratos de compra anticipada de lanas con pequeños y medianos señores de ganado trashumante de zonas rurales, a los que, a cambio de adelantos de dinero, les imponían fuertes descuentos en el precio. Pues cabe presumir que, dado que en estas últimas operaciones se comprometían cantidades muy inferiores de lana, que además se adquirían a unos precios bastante bajos, las mismas conllevaban un riesgo mucho más fácil de asumir.

El análisis de la actividad del soriano Juan Mateo Gutiérrez nos proporciona un buen ejemplo de esta diversificación de estrategias de contratación. Fue, en efecto, un mercader muy activo, que en determinados ejercicios de las décadas de 1660 y 1670 llegó a adquirir cerca de 20.000 arrobas, en gran parte por cuenta de mercaderes foráneos de los que era «correspondiente». Y para desarrollar su actividad puso en práctica una política de contratación muy diversificada. De manera que en un mismo ejercicio con unos ganaderos, en su mayoría pequeños y medianos propietarios, cerraba operaciones de compra adelantada de lanas en otoño, con otros concertaba contratos de obligación en los que se reservaba el derecho a adquirir las lanas si le interesaba, y con otros por fin concertaba contratos en los que se limitaba a exigirles la hipoteca de los ganados y las lanas como garantía de devolución de las cantidades prestadas. Entrar a desvelar las motivaciones que le llevaban en cada caso a elegir un modelo de contratación es tarea que excede las pretensiones del presente trabajo. Pero la propia constatación de esta diversificación de estrategias nos pone muy bien de manifiesto hasta qué punto la contracción del mercado de exportación de lanas castellanas en el tercer cuarto del siglo XVII propició que los mercaderes que actuaban en la región soriana multiplicasen las precauciones, y contribuyó así a colocar a los grandes señores de ganados trashumantes en una difícil e incómoda posición a la hora de negociar la venta de sus lanas.

Pues, este modelo de operación de préstamo, en que los mercaderes se reservaban la capacidad de adquirir las lanas para amortizar la deuda contraída por los ganaderos, resultaba especialmente desventajoso para estos últimos, sobre todo en aquellos casos en que en el contrato firmado a raíz de hacerse efectivo el préstamo se fijaba ya el precio que debería 
pagar el mercader si se decidía por la adquisición de las lanas, y además se establecía una fecha límite muy tardía para que éste manifestase si optaba o no por comprar ${ }^{31}$. Pues estas condiciones dejaban al ganadero escaso margen de maniobra para negociar la venta de sus lanas, ya que debía esperar hasta el mes de junio, o incluso hasta los primeros días de julio, para saber con certeza si el prestamista se quedaba con ellas. En caso de que así fuese corría el peligro de que el precio fijado en su momento para las mismas, por el procedimiento de «atenencias», le resultase desfavorable, por existir en aquel momento algún otro potencial comprador dispuesto a pagárselas a mayor precio. Pero la situación más comprometida se plantearía sin duda en el caso de que le comunicase su indisposición a comprarlas, pues entonces se veía obligado a buscar comprador para ellas y corría el peligro de no encontrarlo, viéndose así privado de una preciosa fuente de ingresos para hacer frente a la amortización de la deuda contraída en el otoño anterior, que habitualmente estaba obligado a realizar en los meses del verano.

En cualquier caso la financiación proporcionada por los mercaderes laneros, tanto si iba unida a compromiso de venta de lanas como si no, pronto dejó de resultar suficiente para satisfacer las crecientes necesidades de los grandes señores de ganados trashumantes sorianos, cada vez más endeudados. Y por consiguiente éstos se vieron forzados a recurrir también a otras fuentes de financiación, que encontraron en prestamistas más o menos profesionales, asentados preferentemente en Madrid, aunque también en menor medida en la propia ciudad de Soria, y en otros núcleos de su entorno como, por ejemplo, Ágreda o Torrecilla de Cameros. Entre estos prestamistas hay que destacar a Diego Ignacio de Córdoba, hombre de negocios de origen cordobés instalado en Madrid, que concedió multitud de préstamos a ganaderos trashumantes sorianos en el tercer cuarto del siglo xvIr ${ }^{32}$. El cual no nos cabe duda de que realizaba estas operaciones con el exclusivo objetivo de percibir un interés por el adelanto del dinero, ya que no tenemos constancia de que participase activamente en el comercio de la lana.

Por un lado, realizó múltiples operaciones de préstamo a muy corto plazo de pequeñas cuantías de dinero a modestos ganaderos trashumantes de las comarcas serranas sorianas. Y una parte importante de las mismas fueron concertadas a comienzos de la primavera, cuando estos últimos nece-

${ }^{31}$ Ejemplos de contratos con este tipo de condiciones en AHPM, 8553-33, Madrid, X-1658 y AHPS, PN, 669-1104-68, Soria, 17-X-1660.

32 Llama la atención sobre la relevancia de este individuo, a quien califica de banquero «prebancario», Bravo Lozano (1986), p. 510. 
sitaban dinero de forma apremiante para pagar los arrendamientos de las dehesas de invernadero. Pues en los contratos que estos ganaderos concertaban con sus propietarios solía fijarse el último, y a veces único, plazo de pago en los últimos días del mes de abril, es decir, en el momento inmediatamente anterior a la salida de los ganados hacia los pastos estivales, que no era autorizada por el señor de la dehesa si previamente no había cobrado el dinero de la renta. Los grandes señores de ganados, por el contrario, dado que disfrutaban de posesiones en las dehesas de la mesa maestral de Alcántara en La Serena, en las que el plazo de pago de los arrendamientos estaba fijado a comienzos del otoño siguiente al abandono de las mismas por los ganados (Diago, 2001a), se veían menos apremiados por esta necesidad de disponer de dinero a fines de la primavera, y por consiguiente recurrieron en muy menor medida a solicitar préstamos en esta estación.

Otro momento en el que Diego Ignacio de Córdoba efectuó numerosos préstamos a pequeños y medianos ganaderos sorianos fue el de comienzos del otoño, cuando éstos o sus mayorales pasaban por Madrid camino de los invernaderos, y necesitaban disponer de dinero con el que atender los numerosos gastos del viaje y la compra de provisiones para pasar el invierno en las dehesas. Durante la estación invernal, por el contrario, apenas efectuaba préstamos en Madrid, pero en contrapartida sí lo hacían sus correspondientes en Córdoba, a quienes acudían con frecuencia los mayorales de los ganaderos sorianos en busca de dinero, el cual les era adelantado con condición de que sus amos lo devolviesen al cabo de unos meses en Madrid al propio Diego Ignacio de Córdoba. Los plazos de devolución de las cantidades recibidas en préstamo en estas operaciones a corto plazo se fijaban en fechas muy diversas, pero hay dos que aparecen con mucha mayor frecuencia, que son, por un lado, finales de mayo, para cuando los ganaderos ya disponían del producto de la venta de sus carneros, y por otro, finales del mes de julio, en concreto el día de Santiago, para cuando ya podían tener vendidas las lanas. Pero además de estos préstamos a corto plazo a medianos y pequeños propietarios, Diego Ignacio de Córdoba también concertó otras muchas operaciones de préstamo a medio y largo plazo con varios de los principales señores de ganados de la oligarquía soriana, a los que adelantó grandes cantidades de dinero para que se las devolviesen en plazos que solían abarcar varios años ${ }^{33}$.

${ }^{33}$ En Madrid, 2-VI-1667, prestó a don Juan Hidalgo de la Puente 124.000 reales de vellón «para pago de hierbas y sustento de ganados», a devolver en tres plazos en San Miguel de 1668,1669 y 1670 . AHPM, 8555-105. En 1686 se le seguían adeudando todavía 
Contemporáneo de Diego Ignacio de Córdoba fue Juan García del Pozo, hombre de negocios nacido en Soria e instalado desde muy joven en Madrid, que también desarrolló un activo papel como prestamista de ganaderos sorianos, en nombre de los cuales realizó además multitud de operaciones de cobros, pagos y transferencias de dinero, cual si de un banquero propiamente dicho se tratase (Diago, 1999). Y a estos dos nombres destacados habría que añadir otros muchos, cuyas trayectorias merecerían ser analizadas con mayor detalle en un trabajo sobre el crédito en el Madrid del siglo Xvil, que esperamos pueda llevarse a cabo en un futuro no demasiado lejano.

\section{CONCLUSIONES}

Aunque no hay que descartar que en ferias y mercados tuviesen lugar operaciones de compraventa de lanas en las que no interviniese el crédito, no cabe duda de que el grueso de la contratación lanera en la región soriana en los siglos XVI y XVII llevó aparejadas operaciones de crédito de muy diversa envergadura, que necesariamente han de ser valoradas para poder explicar satisfactoriamente no sólo el funcionamiento del mercado lanero, sino también las diferencias de rentabilidad de las explotaciones ganaderas, tanto estantes como trashumantes.

En este sentido creemos que ha podido quedar suficientemente demostrado que las pequeñas explotaciones, y muy en particular las de ganado estante, en todo momento se situaron en una posición muy desventajosa para resultar rentables, porque tanto en el siglo xvi como en el xvir resultaron excesivamente dependientes del crédito que les proporcionaban los mercaderes, y por consiguiente no pudieron conseguir precios satisfactorios para la mercancía que les proporcionaba la principal fuente de ingresos, la lana. Pero habría que precisar que en el caso de las explotaciones ganaderas estantes esta dependencia era resultado ante todo de la propia precariedad de las economías domésticas de muchos de los campesinos sorianos de la época, que pedían prestado no sólo para atender los gastos que generaba la explotación de sus diminutos rebaños, sino también para hacer frente a otras múltiples necesidades domésticas.

36.567 reales de este préstamo. AHPS, PN, 2830-4855-92. El regidor Juan de Salazar y Salcedo al morir, poco antes de 1677 , le estaba debiendo 113.000 reales de restos de varios préstamos. AHPM, 8559-326. 
Dejando a un lado, pues, el caso de los ganaderos estantes, entre los trashumantes no cabe duda de que la dependencia del crédito para poder atender al sostenimiento de la explotación ganadera fue mayor entre los pequeños y medianos propietarios que entre los grandes, sobre todo durante el siglo XVI y en las primeras décadas del siglo XVII. Y esto propició que entonces las grandes explotaciones resultasen mucho más rentables, porque pudieron vender la lana a precios muy ventajosos, aunque hay que reconocer que en determinados momentos del siglo xvi la bonanza económica alcanzó igualmente a un gran número de explotaciones ganaderas de tamaño mediano e incluso pequeño, que también consiguieron en algunos ejercicios dejar de depender para su funcionamiento del crédito proporcionado por los mercaderes, y pudieron obtener por tanto precios muy remuneradores para sus lanas, a cambio de conceder muy breves aplazamientos de pago a quienes las compraron.

La aparición de las primeras graves dificultades en el mercado internacional lanero en la década de 1570, que se fueron agravando en las décadas siguientes, imprimieron un giro radical a esta situación. Y a partir de entonces cada vez mayor número de explotaciones ganaderas trashumantes pasaron a depender del crédito para tener asegurado su regular funcionamiento, aunque las grandes tardaron mucho más que las medianas y pequeñas en caer en esta situación de dependencia, y no lo hicieron de forma irreversible hasta mediados del siglo XVII.

Pero, en última instancia, fueron los propietarios de estas grandes explotaciones los que en el transcurso del tiempo resultaron víctimas de una más brutal alteración de su posición en el mercado, pues pasaron de poder almacenar lanas de varios esquileos y venderlas a pago aplazado a los mercaderes, a mediados del siglo xv, a tener que solicitar reiteradamente préstamos para atender los gastos que generaba la gestión de dichas explotaciones, sin que los ingresos que les reportaban resultasen suficientes para amortizarlos en los plazos previstos, a mediados del siglo XVI.

De hecho, al analizar la trayectoria de las grandes explotaciones ganaderas trashumantes sorianas en la segunda mitad del siglo XVII, sorprende la tenacidad con que las familias propietarias de éstas se aferraron a conservarlas en un contexto que aparentemente invitaba a deshacerse de ellas, porque cada vez resultaba más difícil hacerlas rentables, y era grande el riesgo de incurrir con ellas en considerables pérdidas. Y esta persistencia de las mismas familias al frente de las principales explotaciones ganaderas trashumantes contrasta además con la constante renovación del grupo de mercaderes que negociaban con las lanas producidas por las mismas. Pero 
no hay lugar aquí para entrar a determinar las razones que podrían explicar este paradójico fenómeno.

\section{BIBLIOGRAFÍA}

Basas Fernández, Manuel (1961): «Burgos en el comercio lanero del siglo XVI», Moneda y Crédito, núm. 77, pp. 37-68.

- (1963): El Consulado de Burgos en el siglo XVI, Madrid, CSIC.

BENTTO RUANO, Eloy (1975): «Lanas castellanas. ¿Exportación o manufacturas?», Archivium, XXV, pp. 123 ss.

BlLBAO, Luis María (1983): «Exportación y comercialización de lanas de Castilla durante el siglo XVI, 1610-1720», en El pasado bistórico de Castilla y León, vol. 2, Edad Moderna, Burgos, Junta de Castilla y León.

Bllbao, Luis María, y Fernández Pinedo, Emiliano (1986): «Exportación de lanas, trashumancia y ocupación del espacio en Castilla durante los siglos XVI, XVI y xvins, en Garcia Martin, Pedro, y Sánchez Benito, José María (eds.): Contribución a la historia de la trashumancia en España, Madrid, Ministerio de Agricultura, Pesca y Alimentación.

Bravo Lozano, Jesús (1986): «Don Francisco de Horcasitas. Las posibilidades de Madrid a fines del siglo XvI», Estudios de Historia Social, núm. 36-37, pp. 497-521.

BrumONT, Francis (1984): «La laine dans la région de Nájera (deuxième moitié du XVle. siècles)», en Actas del II Coloquio de Metodologia Histórica Aplicada. La documentación notarial y la bistoria, t. II, Santiago de Compostela, pp. 317-22.

BurTON, Janet (1994): Monastic and Religious Orders in Britain. 1000-1300, Cambridge, Cambridge University Press.

CalataYud, $P$. (1761): Tratados y doctrinas prácticas sobre ventas y compras de lanas merinas, $y$ otros géneros; $y$ sobre el juego de naypes, y dados con un suplemento de veinte y seis contratos, Toledo.

CARRIÓN DE ÍsCAR, Francisco Javier (1995): «El negocio lanero en el comercio burgalés, 1547-1575», en CASADO Alonso, Hilario (ed.): Castilla y Europa. Comercio y mercaderes en los siglos XIV, XV y XVI, Burgos, Diputación Provincial, pp. 160-1.

CASAdO Alonso, Hilario (1994): «El comercio internacional burgalés en los siglos XV y XVI», en Actas del V Centenario del Consulado de Burgos (1494-1994), Burgos, Diputación Provincial.

Diago Hernando, Máximo (1989): «El comercio de la lana en Soria en época de los Reyes Católicos», Celtiberia, núm. 77-78, pp. 25-75.

- (1991): «El comercio de las lanas churras en el ámbito soriano durante el siglo xvi», Chronica Nova, núm. 19, pp. 87-111.

- (1993): «Caballeros y ganaderos. Evolución del perfil socioeconómico de la oligarquía soriana en los siglos XV y XVI», Hispania, núm. 184, pp. 451-95.

- (1994): «Grandes y pequeños ganaderos trashumantes en las sierras sorianas en el tránsito de la Edad Media a la Edad Moderna», Revista de Historia Económica, XII, núm. 2, pp. 343-364. 
- (1999): «Juan García del Pozo y las relaciones económicas entre Madrid y Soria en el siglo XVI», Anales del Instituto de Estudios Madrileños, núm. 39, pp. 183-212.

- (2000a): «El papel de la lana en las relaciones económicas entre Soria y las villas pañeras cameranas en los siglos XVI y XVII», Berceo, núm. 138, pp. 61-90.

- (2000b): «Los hombres de negocios en la ciudad de Soria durante el siglo XVI», Hispania, núm. 205, pp. 479-514.

- (2001a): «El acceso a las dehesas de La Serena por los ganaderos trashumantes sorianos. 1590-1650», Historia Agraria, núm. 23, pp. 55-77.

- (2001b): «Los mercaderes navarros en el comercio de exportación de lanas de la región soriana durante el siglo XVII», Principe de Viana, núm. 222, pp. 139-165.

Falah Hassan Abed Al-Hussein (1986): «Las ferias de Medina y el comercio de la lana: 1514-1573», en Historia de Medina del Campo y su Tierra, vol. II, Valladolid, pp. 15-66.

Garcia Sanz, Angel (1977): Desarrollo y crisis del Antiguo Régimen en Castilla la Vieja: Economia y sociedad en tierras de Segovia, 1500-1814, Madrid, Akal.

KerSHaw, Ian (1973): Bolton Priory. The economy of a northern monastery, 1286-1325, Oxford University Press.

LAPEYRE, Henri (1981): El.comercio exterior de Castilla a través de las aduanas de Felipe II, Valladolid, Universidad.

LLOPIS AGELÁN, Enrique (1980): «Crisis y recuperación de las explotaciones trashumantes: La cabaña del Monasterio de Guadalupe (1579-1679)», Investigaciones Económicas, núm. 13, pp. 125-i68.

- (1982): «Las explotaciones trashumantes en el siglo xviI y el primer tercio del Xxx: la cabaña del Monasterio de Guadalupe, 1709-1835", en ANES, Gonzalo (ed.): La economía española al final del Antiguo Régimen, I, Agricultura, Madrid, Alianza Editorial, pp. 1-101.

- (1998): «Medio siglo de una gran explotación trashumante: la cabaña merina del Monasterio de El Paular, 1680-1730», en Ruiz Martín y García Sanz (eds.), pp. 144-197.

Pérez Romero, Emilio (1999): «La trashumancia desde las sierras sorianas: La hegemonía de las grandes cabañas», en Extremadura y la trashumancia (siglos XVI-XX), Mérida, Junta de Extremadura, 1999, pp. 35-54.

PHILIPPS, Carla Rahn y William D. (1997): Spain's Golden Fleece. Wool production and the Wool Trade from the Middle Ages to the Nineteenth Century, Baltimore-Londres, The Johns Hopkins University Press.

Ruiz Martin, Felipe, y Garcia Sanz, Ángel (eds.) (1998): Mesta, trashumancia y lana en la España Moderna, Barcelona, Crítica. 